\title{
PROTECTIVE EFFECT OF CURCUMIN ON DIFFERENT TISSUES OF RAINBOW TROUT (ONCORHYNCHUS MYKISS W., 1792) AGAINST EXPOSITION TO CHLORPHYRIFOS
}

\author{
ŞAHINÖZ, E. ${ }^{1}$ - ARAL, F. ${ }^{2}-$ DOĞU, Z. ${ }^{1 *}-$ KOYUNCU, I. $^{3}-$ YÜKSEKDAĞ, Ö. ${ }^{3}$ \\ ${ }^{I}$ Department of Fisheries and Aquaculture, Bozova Vocational School, Harran University \\ Şanlıurfa, Turkey \\ ${ }^{2}$ Department of Reproduction and Artificial Insemination, Faculty of Veterinary Medicine, \\ Harran University, Şanliurfa, Turkey \\ ${ }^{3}$ Department of Medical Biochemistry, Faculty of Medicine, Harran University \\ Şanliurfa, Turkey \\ *Corresponding author \\ e-mail: zaferdogu@harran.edu.tr, zafer_dogu@yahoo.com; phone: +90-414-318-3258; fax: \\ $+90-414-318-3260$ \\ (Received $13^{\text {th }}$ Dec 2018; accepted 20 ${ }^{\text {th }}$ Feb 2019)
}

\begin{abstract}
In this study, protective effects of Curcumin (CUR) against Chlorphyrifos (CPF)-induced oxidative stress on blood serum, liver and gill tissues of rainbow trout (Oncorhynchus mykiss) were investigated. In the first group, normal water and recommended diet were used as the control group. The second fish group was exposed to water containing $0.040 \mathrm{mg} / \mathrm{l} \mathrm{CPF}$. The third fish group received only $0.5 \%$ (CUR1) and the fourth group received only $1 \%$ CUR (CUR2). The fifth group was exposed to water containing $0.040 \mathrm{mg} / \mathrm{l} \mathrm{CPF}$ and received only $0.5 \%$ (CPF + CUR 1 ). The sixth group was exposed to water containing $0.040 \mathrm{mg} / \mathrm{l} \mathrm{CPF}$, giving and received only $0.1 \%$ (CPF + CUR2). Samples were taken from the blood, liver and gill tissues and total antioxidant capacity (TAC), total oxidant status (TOS) and oxidative stress index (OSI) were measured. The supplementation of CUR with CPF attenuated the adverse effects of CPF intoxication by reducing TOS and OSI and increased TAC in serum and liver. These results showed that CPF, alone, increased oxidative stress in rainbow trout but CUR reduced oxidative stress alone or when combined with CPF in the serum and liver, but not in the gill.
\end{abstract}

Keywords: insecticides, turmeric, liver, gill, blood antioxidant, fish

\section{Introduction}

Pesticides are synthetic or organic compounds used to destroy organisms that negatively affect human activities. The pesticides used in the struggle against weeds, insects and other harmful substances in the fields where the cultivated plants are grown pollute to the groundwater sources in various forms and can reach aquatic environments through infiltration (Karacan, 2007). Chlorpyrifos (CPF) [O, O-diethyl O- (3, 5, 6trichloro-2-pyrrolidyl)-phosphorothioate)] is a broad-spectrum organophosphorus insecticide used to control insect and arthropod populations in agricultural areas (GirónPérez et al., 2006). CPF, which has low water solubility, directly affects neurotransmission through inhibiting acetylcholinesterase activity in the organism. Unlike other organophosphorous pesticides, CPF has a long lasting effect and accumulates in fat tissues (Kammerbauer and Moncada, 1998).

In aquatic environments, living creatures, especially fishes, are primarily affected by pesticides. In genotoxicity studies in aquatic environments, various tests that were prepared for mammals in order to determine the clastogenic effects of chemical 
substances, have been modified in different ways and used on aquatic creatures such as especially fish, mussels and other crustaceans (Burgeot et al., 1995; Sanchez-Galan et al., 1998). In acute toxicity studies, it has been reported that 50-70\% mortality was seen in Aulacomya ater (Molina, 1782) (Bivalvia: Mytilidae) at $0.050 \mathrm{mg} / \mathrm{l} \mathrm{CPF}$ levels and inhibited enzyme activity of 0.02-0.16 mg/l acetylcholinesterase (Fuhrer et al., 2012).

Curcumin (CUR) has many effects such antiinflammatory, antioxidant, anticancerogenic, antimutagenic, anticoagulant, antidiabetic, antibacterial, antiviral and nerve preservative effects in a broad spectrum which is made of turmeric/curcuma that is used as a spice and gives yellow color to the meals (Turmeric, Curcuma longa) (Naik et al., 2011). CUR has been extensively investigated for its protective effect on the cardiovascular system, as it facilitates the release of many reactive oxygen radicals, especially superoxide anions, nitrogen dioxide radicals and hydroxyl radicals (Sreejayan, 1997; Duan et al., 2012). In these studies, CUR has been shown to inhibit endotelial and smooth muscle cells from damage (Srivastava and Mehta, 2009), to prevent heart damage (Nirmala et al., 1999), to accelerate the restructuring of heart and vessels have been reported to improve oxidative damage (Morimoto et al., 2008; Bala et al., 2006).

Among all creatures living in aquatic environments, fish have a very important place in the use of these tests because they can be easily kept, fed and grown up in laboratory environments. Akdemir et al. (2016) investigated the effects of different rates of CUR on the growth performance of trout and reported that CUR extract reduced the negative impact of high stocking intensity on performance of rainbow trout. Cao et al. (2015) found that Carp (Cyprinus carpio) which are fed CUR at different doses for 60 days increased their oxidative tolerance to carbon tetrachloride-induced liver damage. Similarly, the protective effect of CUR on the Anabas testudineus (Bloch) was studied and for this purpose, fish were fed for 2 to 8 weeks with fish feed to which two doses of CUR $(0.5 \%$ and $1 \%)$ was added. As a result of the research, the antioxidant status, protein content and texture of fish were investigated acutely and chronically. In all groups fed with CUR, the lipid peroxidation value was reduced or unaffected. The antioxidant enzyme activity level is increased as the glutathione level changes depending on the time and the dose. In addition, the protective effect of CUR was also determined in histological analyzes (Manju et al., 2012).

Organophosphates are the insecticides most commonly used worldwide in the pest control of crops. The global pesticide market is growing at around $1 \%$ per annum as tonnage. Herbicides are ranked first in agrochemicals with a share of $47 \%$. This is followed by insecticides by $29 \%$ and fungicides by $19 \%$. Herbicides and insecticides that make up more than $70 \%$ of agricultural drugs are distributed around the land use (Dağ et al., 2000). The effects of these pesticides are different according to the environment and amount of accumulation. CPF is commonly used in agricultural areas around the dam reservoir (EPDA, 2004).

Organophosphorus insecticide (OPI) has been reported to alter oxidative stress characteristics (Malkovics, 1995). Recent studies on pesticide poisoning have highlighted the oxidative stress caused by free radicals produced by pesticides. The generation of hydrogen peroxide $\left(\mathrm{H}_{2} \mathrm{O}_{2}\right)$ is catalyzed by the dismutation reaction of superoxide dismutase (SOD) and superoxide anion $\left(\mathrm{O}_{2}^{-}\right)$. Hydrogen peroxide is catalytically decomposed by water (CAT) activation and molecular oxygen. If the free radical production crosses endogenous antioxidant levels, they can lead to cell damage or death (Malkovics, 1995; Zámocký et al., 1999). 
CPF intoxication has been shown to significantly reduce reduced glutathione (GSH), catalase (CAT) and glutathione S-transferase (GST) activities in the rat liver. As a result of zinc treatment, CPF-treated animals have been shown to have an elevation in the levels of GSH, catalase and GST, as well as a significant decrease in the levels of SOD (Goel et al., 2005).

Dimethoate, an organophosphate pesticide, has been reported to increase catalase, (CAT), superoxide dismutase (SOD), glutathione peroxidase (GPx) and glutathione reductase (GR) activity in hepatic cytochrome P450 enzymes, brain and liver lipid peroxidation in acutely exposed male rats (Sharma et al., 2005).

These results show that organophosphorus (CPF) may be an oxidant. This study is important because the treatment of CPF exposed fish and CUR is also important in preventing toxic effects. Therefore, it is aimed to determine the protective effect of CUR against the toxic effect of Chlorpyrifos. There was no information on this subject in the literature search.

In this context it is planned within three main objectives; 1) to investigate the oxidative stress of CPF in some tissues 2) to examine the effects of CUR alone on the oxidative mechanism 3) to determine the protective effects of CUR on the oxidative stress resulting from CPF toxicity. So, the protective effects of Curcumin against chlorpyrifos-induced oxidative stress on serum, liver and gill tissues of rainbow trout (Oncorhynchus mykiss) were investigated.

\section{Materials and methods}

\section{Materials}

\section{Chemicals}

CUR, CPF (96.5\% purity (technical grade)), were purchased from Sigma Chemicals (Sigma-Aldrich, Turkey). All other chemicals were purchased from standard commercial suppliers (St Louis, MO, USA).

In the study; the establishment and implementation of the feeding experiment was carried out in concrete pools in the Department of Fisheries and Aquaculture at Harran University Bozova Vocational School for Higher Education for 30 days. 120 male rainbow trout (O. mykiss) (2 replicate) of 2 years old, with an average weight of 80$100 \mathrm{~g}$, were obtained from Karacalar Food, Agriculture, Aquaculture Import and Export Limited Company. Water temperature, $\mathrm{pH}$ and dissolved oxygen were $15.0 \pm 1.5^{\circ} \mathrm{C}$, $7.8 \pm 0.9$ and $8.8 \pm 0.3 \mathrm{mg} / \mathrm{L}$, respectively.

It is produced from marine raw materials and have high digestibility and high protein content supplied from a commercial company.

$\mathrm{CPF}$ was dissolved in acetone as stock solution $(0.1 \%)$ and this stock solution was mixed into pools at defined ratios. It was stored at $4{ }^{\circ} \mathrm{C}$ and from these daily requirements is added to pools. The use of fish and experimental application protocols were supervised by the Dollvet A.Ş. Animal Experiments Local Ethics Committee (Şanlıurfa-Turkey). Analyzes of the tissues were carried out at Harran University Biology Department laboratories.

\section{Methods}

Rainbow trout was kept in 5001 pools with continuous aeration for 30 days. In the study, pellet trout feed was given two times a day as once in the morning and once in 
the evening for feeding fish in the pools which shall be ventilated continuously. The stock solutions of CPF, the pesticide, given to the environment where fish live, were prepared and the water in the pools was changed by $1 / 3$ per day. CUR, which will be used in the study, is adjusted to $0.5 \%$ and $1.0 \%$ of the total weight of the fish (Manju et al., 2012). The CUR extract was dissolved in DMSO and stock solutions were prepared in PBS at $\mathrm{pH} 7.2$ and given intraperitoneally to fish. The fish was placed in 12 pools as 10 fishes (2 replicates) in each pool. Fish were divided into 6 groups (control group, CPF, CUR1, CUR2, CPF + CUR1, CPF + CUR2). In the first group, normal water was used as the control group and the fish were given feed without additives (Control). The second fish group was exposed to water containing $0.040 \mathrm{mg} / \mathrm{l} \mathrm{CPF}$ (Doğu et al., 2015). The third fish group received only $0.5 \%$ CUR (CUR1), received eight doses (two doses per week) of CUR by intraperitoneal injections (IP) and the fourth group received only $1 \%$ CUR (CUR2), received eight doses (two doses per week) of CUR by IP. The fifth group was exposed to water containing $0.040 \mathrm{mg} / \mathrm{L} \mathrm{CPF}$ and given CUR (CPF + CUR1) at a rate of $0.5 \%$ of the total weight of the fish, received eight doses (two doses per week) of CUR by IP. The sixth group was exposed to water containing $0.040 \mathrm{mg} / \mathrm{L} \mathrm{CPF}$ and given CUR (CPF + CUR2) at $1.0 \%$ of the total weight of the fish, received eight doses (two doses per week) of CUR by IP. Experimental conditions are summarised in Table 1 .

Table 1. Experimental design of the study

\begin{tabular}{c|c|c|c|c|c|c}
\hline & \multicolumn{7}{|c}{ Experimental groups } \\
\cline { 2 - 7 } & Control & CPF & CUR1 & CUR2 & CPF+CUR1 & CPF+CUR \\
\hline CPF (mg/l) & - & 0.040 & - & - & 0.040 & 0.040 \\
CUR (\%) & - & - & 0.5 & 1 & 0.5 & 1 \\
\hline
\end{tabular}

At the end of the study $0.6 \mathrm{~mL} / \mathrm{L}$ 2-phenoxyethanol was administered as an anesthetic agent before taking blood samples from all experimental groups. Subsequently, blood samples from each fish were transferred individually to heparinized test tubes. The anesthetized fish were rinsed with distilled water prior to the dissections to avoid the external pesticide residue.

Fish were dissected and liver and gill tissue were collected and stored at $-20{ }^{\circ} \mathrm{C}$ for examination. Blood from the fish was transferred to EDTA glass tubes and allowed to stand at $+4{ }^{\circ} \mathrm{C}$ at $3000 \mathrm{rpm}$ for $1 \mathrm{~h}$ at $+4{ }^{\circ} \mathrm{C}$ before being centrifuged for $15 \mathrm{~min}$ by refrigerated centrifugation. After centrifugation, the plasma was separated from the erythrocytes and blood samples were stored at $-20{ }^{\circ} \mathrm{C}$ until the enzymatic antioxidants were examined. Then the following tests were applied. Liver and gill were collected and perfused with isotonic salt solution $(0.9 \% \mathrm{NaCl})$ to remove blood and others and used for preparation of tissue homogenate.

\section{Preparation of tissues homogenate}

The whole liver and gill tissues were homogenized in phosphate saline buffer $(100 \mathrm{mM})$ containing EDTA $(1 \mathrm{mM} ; \mathrm{pH} 7.4 ; 1: 10 \mathrm{w} / \mathrm{v})$ and then centrifuged $(12,000 \times \mathrm{g}$, $\left.30 \mathrm{~min}, 4^{\circ} \mathrm{C}\right)$. The supernatant was separated and used for biochemical analysis. 


\section{Oxidative stress test}

Total antioxidant status (TAC)

Intracellular total oxidant capacity (TAC) was measured using Rel Assay Diagnostics total oxidant capacity measurement kit (Gaziantep/Turkey). In this measurement method, 2,2' -azinobis- (3-ethylbenzothiazoline-6-sulfonic acid) radical (ABTS radical) is used. ABTS radical loses its blue and green color (faded) according to antioxidant concentration and antioxidant capacity. This color change is assessed by measuring the absorbance value at $660 \mathrm{~nm}$. The principle of this measurement method is based on the fact that the ABTS molecule in the presence of hydrogen peroxide is oxidized to the ABTS+ molecule. The color of radical which is dark brown at $30 \mathrm{mmol} / \mathrm{L}$ acetate buffer and $\mathrm{t} \mathrm{pH}: 3.6$ is faded at $0.4 \mathrm{~mol} / \mathrm{L}$ acetate buffer and $\mathrm{pH}: 5.8$. There is an inverse relationship between color change and the amount of antioxidant in the sample. The reaction rate was expressed as Trolox equivalent/L by calibrating with the standard method Trolox (Erel, 2005).

\section{Total oxidant status (TOS)}

Intracellular total oxidant status (TOS) was measured by using Rel Assay Diagnostics total oxidant capacity measurement kit (Gaziantep/Turkey). In this method; Reagent 1: The main solution is prepared by dissolving $25 \mathrm{mM} \mathrm{H}_{2} \mathrm{SO}_{4}$ in $140 \mathrm{mM} \mathrm{NaCl}$ solution. The main solution is prepared by first dissolving 10\% glycerol and then dissolving $250 \mu \mathrm{M}$ xylenol orange in total volume. Reagent 2: Reagent is prepared by dissolving $10 \mathrm{mM}$ o-Dianisidine dihydrochloride in the main solution and then dissolving $5 \mathrm{mM}$ ammonium ferrous sulphate. Principle: The oxidants present in the sample oxidize the ferrous ion-o-dianisidine complex to the ferric ion. The glycerol in the medium accelerates this reaction to about three fold. Ferric ions form a colored complex with xylenol orange in acidic environment. The intensity of the color associated with the amount of oxidants present in the sample will be measured spectrophotometrically, in units of $\mathrm{mol} \mathrm{H}_{2} \mathrm{O}_{2}$ Eqv./L (Erel, 2005).

Oxidative stress index (OSI)

The TOS: TAC ratio was used as the oxidative stress index (OSI). To perform the calculation, the units of TAC, mmol Trolox equivalent/L, was converted to $\mu$ mol Trolox equivalent/L. OSI was calculated and expressed as Unit AU (Arbitrary Unit) and as shown the formula below (Erel, 2005):

$$
\text { OSI }=(((\mathrm{TOS}, \mu \mathrm{mol} / \mathrm{L}) /(\mathrm{TAC}, \mu \mathrm{mol} \text { Trolox equivalent/L })) / 100)
$$

\section{Statistical analysis}

Statistical analysis of the data was carried using SPSS 16.0 software. Analysis of variance (ANOVA) and Tukey' post hoc test was employed to compare the differences in TOS, TAC and OSI in the serum, liver and gill. A $p$ value less than 0.05 was considered as statistically significant. All data are expressed as mean $\pm \mathrm{SE}$. 


\section{Results}

The results of the examined parameters of blood serum are given in Figures 1, 2 and 3. There were significant differences in serum TOS, TAC and OSI values $(p<0.001)$ in serum. Serum TAC was similar when compared to the control groups given CUR $0.5 \%$ and $1 \%$. The serum TAC values of the CPF group were significantly lower than those of the CUR-1 group. When combined CUR with CPF, serum TAC values were significantly lower than those of the groups which were given only CUR-1. When compared with the control, the highest TOS was obtained in the CPF group, whereas the TOS values of the CUR-treated groups and CPF+CUR in both doses were similar. CUR (0.5\% and $1.0 \%$ quantities) supplied with CPF significantly reduced the TOS values when compared to the CPF group in serum. Serum OSI were significantly higher in $\mathrm{CPF}$ groups compared to control group $(p<0.001)$. There were no significant differences between control and Curcumin groups, control and CPF+CUR groups in OSI, except CPF+CUR2 in OSI (Fig. 3).

The results of the examined parameters of liver tissue are given in Figures 4, 5 and 6. Significant differences were observed between the groups in liver TOS, TAC and OSI values $(p<0.001)$. Liver TOS values were lowest in the CUR group and the highest in the CPF group compared with the control group. In the CPF + CUR group, TOS were significantly lower than in the CPF group, although similar to the control group. Liver TAC was found to be at the highest level of CUR $1.0 \%$ when compared with the control group. The $\mathrm{CPF}$ group had the lowest TAC compared to the control group. Liver OSI was the lowest in the CPF group and the highest in CUR group compared to the control group, but similar in the other groups.

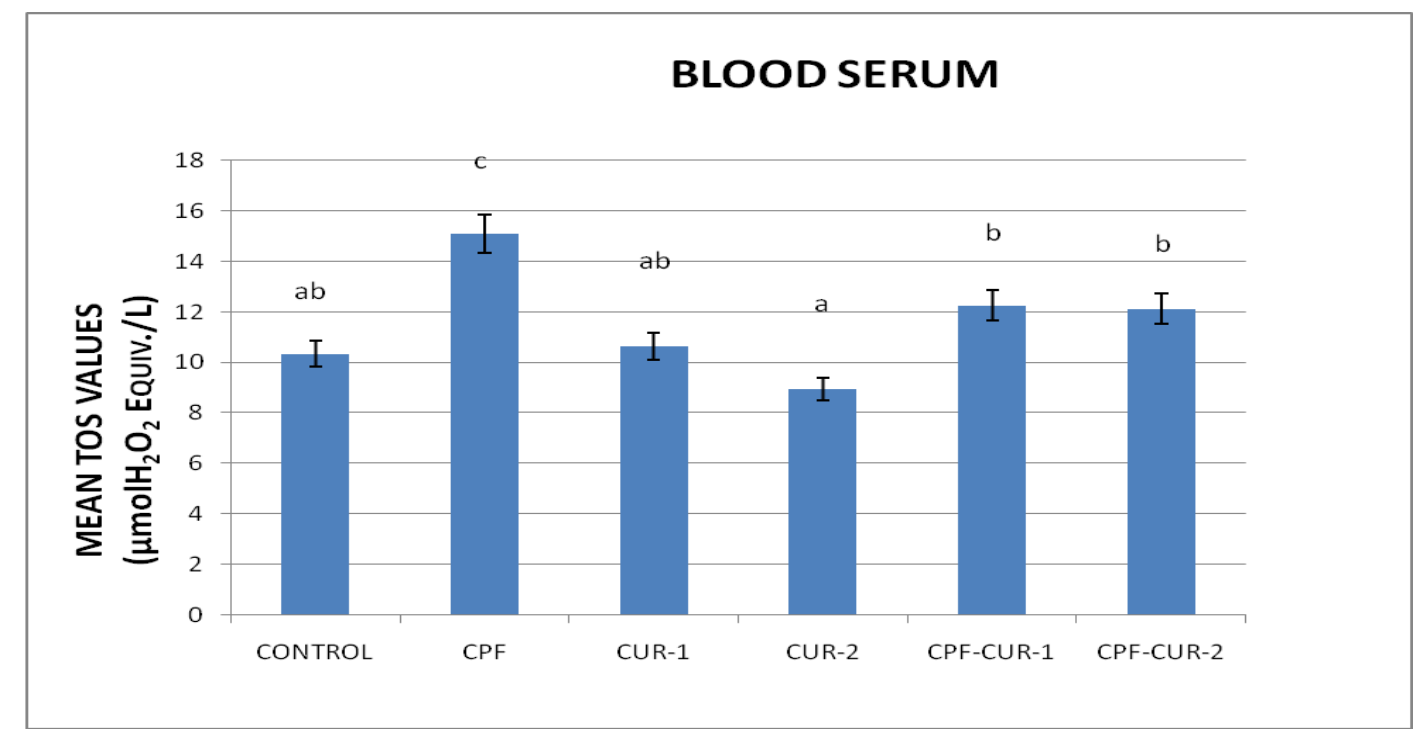

Figure 1. Effect of CPF and Curcumin on TOS values of blood serum in O. mykiss $(n=10)$. Control: The fish was fed with pellet without additives. CFP (Chlorpyrifos): The group was exposed to water containing $0.040 \mathrm{mg} / \mathrm{l} C P F$. CUR1: The group received only $0.5 \%$ Curcumin. CUR2: The group received only 1\% Curcumin. CPF + CUR1: The group was exposed to water containing $0.040 \mathrm{mg} / \mathrm{CPF}$, giving Curcumin at a rate of $0.5 \%$ of the total weight of the fish. $C P F+C U R 2$ : The group was exposed to water containing $0.040 \mathrm{mg} / \mathrm{l} C P F$, giving Curcumin at $1.0 \%$ of the total weight of the fish. All data are presented in mean $\pm S E(n=20)$. abc: Bars bearing common letters are not statistically different $(p>0.05)$. There was a significant difference between the groups $(p<0.001)$ 


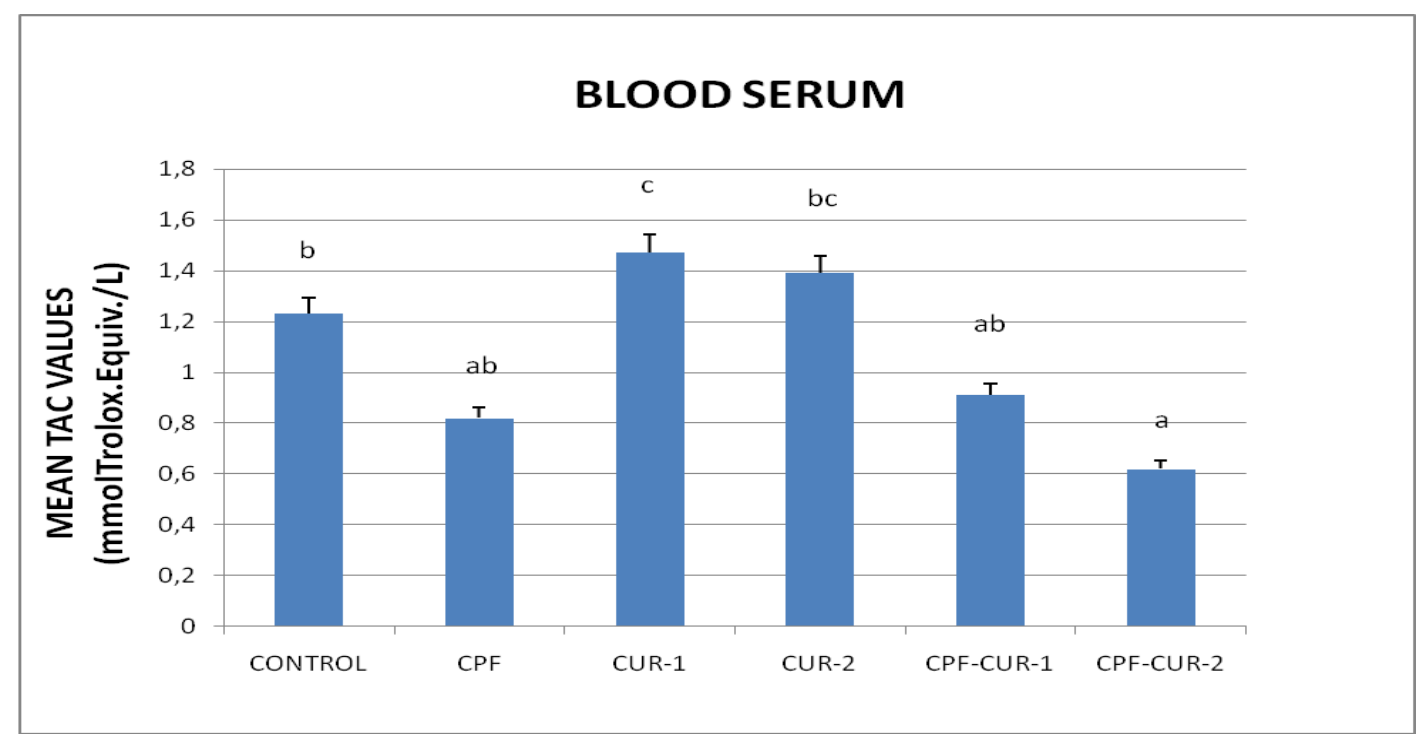

Figure 2. Effect of CPF and Curcumin on TAC values of blood serum in $O$. mykiss $(n=10)$. Control: The fish was fed with pellet without additives. CFP (Chlorpyrifos): The group was exposed to water containing $0.040 \mathrm{mg} / \mathrm{l} \mathrm{CPF}$. CUR1: The group received only $0.5 \%$ Curcumin. CUR2: The group received only $1 \%$ Curcumin. CPF + CUR1: The group was exposed to water containing $0.040 \mathrm{mg} / \mathrm{l} C P F$, giving Curcumin at a rate of $0.5 \%$ of the total weight of the fish. $C P F+C U R 2:$ The group was exposed to water containing $0.040 \mathrm{mg} / \mathrm{l} \mathrm{CPF}$, giving Curcumin at $1.0 \%$ of the total weight of the fish. All data are presented in mean $\pm S E(n=20)$. abc: Bars bearing common letters are not statistically different $(p>0.05)$. There was a significant difference between the groups $(p<0.001)$

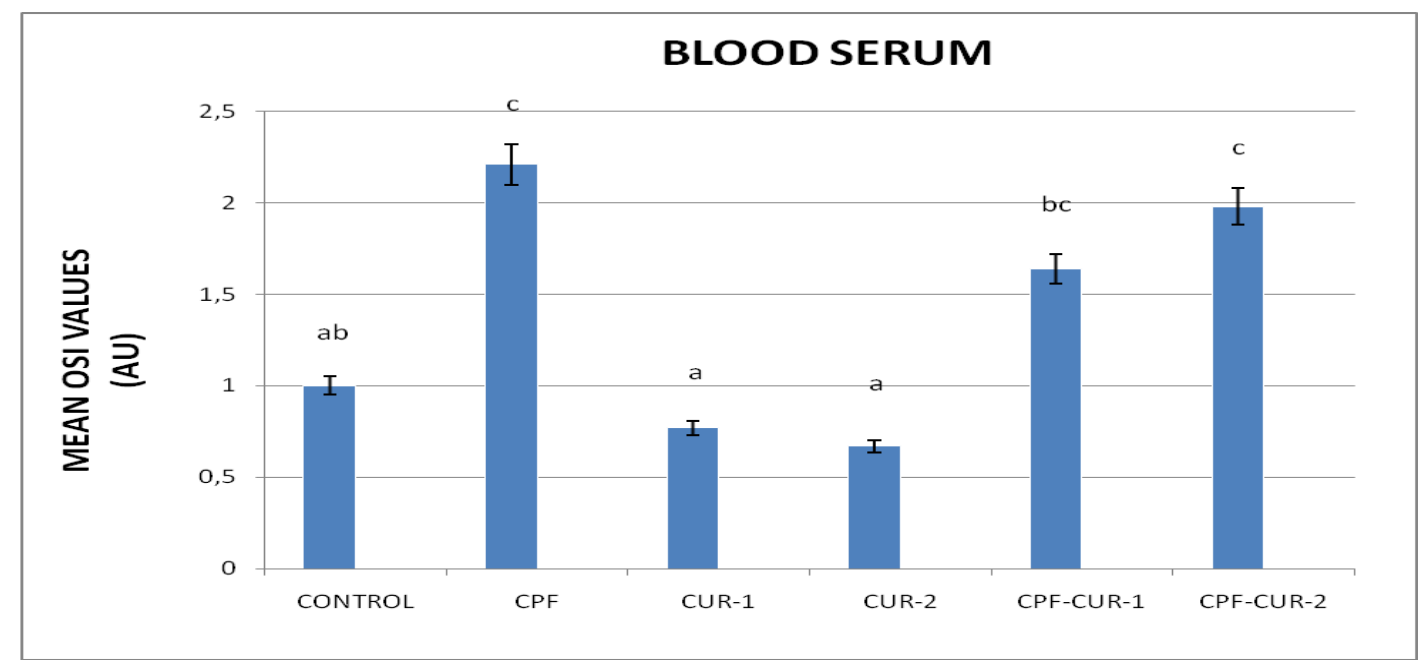

Figure 3. Effect of CPF and Curcumin on OSI values of blood serum in O. mykiss $(n=10)$. Control: The fish was fed with pellet without additives. CFP (Chlorpyrifos): The group was exposed to water containing $0.040 \mathrm{mg} / \mathrm{CPF}$. CUR1: The group received only $0.5 \%$ Curcumin. CUR2: The group received only 1\% Curcumin. CPF + CUR1: The group was exposed to water containing $0.040 \mathrm{mg} / \mathrm{l} C P F$, giving Curcumin at a rate of $0.5 \%$ of the total weight of the fish. $C P F+C U R 2:$ The group was exposed to water containing $0.040 \mathrm{mg} / \mathrm{l} C P F$, giving Curcumin at $1.0 \%$ of the total weight of the fish. All data are presented in mean $\pm S E(n=20)$. abc: Bars bearing common letters are not statistically different $(p>0.05)$. There was a significant difference between the groups $(p<0.001)$ 


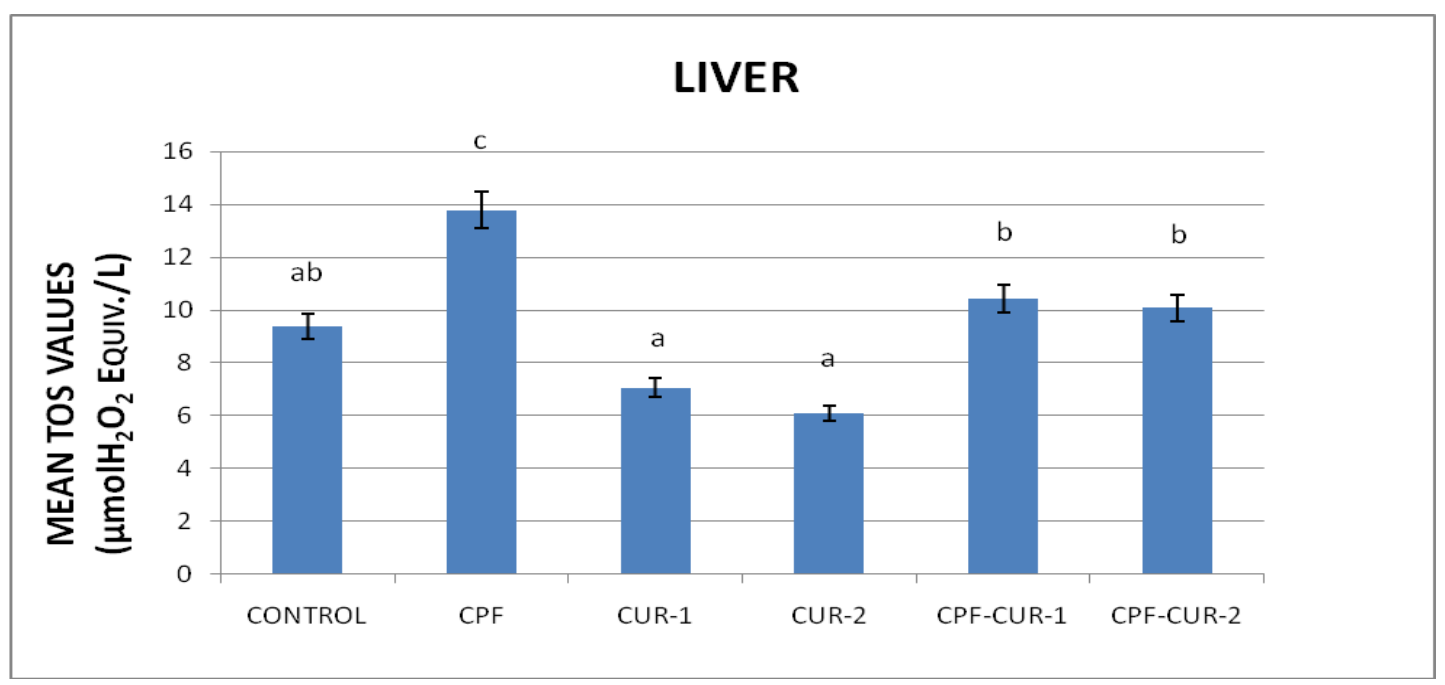

Figure 4. Effect of CPF and Curcumin on TOS values of liver tissue in O. mykiss $(n=10)$. Control: The fish was fed with pellet without additives. CFP (Chlorpyrifos): The group was exposed to water containing $0.040 \mathrm{mg} / \mathrm{CPF}$. CUR1: The group received only $0.5 \%$ Curcumin. CUR2: The group received only 1\% Curcumin. CPF + CUR1: The group was exposed to water containing $0.040 \mathrm{mg} / \mathrm{CPF}$, giving Curcumin at a rate of $0.5 \%$ of the total weight of the fish. $C P F+C U R 2:$ The group was exposed to water containing $0.040 \mathrm{mg} / \mathrm{l} C P F$, giving Curcumin at $1.0 \%$ of the total weight of the fish. All data are presented in mean $\pm S E(n=20)$. abc: Bars bearing common letters are not statistically different $(p>0.05)$. There was a significant difference between the groups $(p<0.001)$

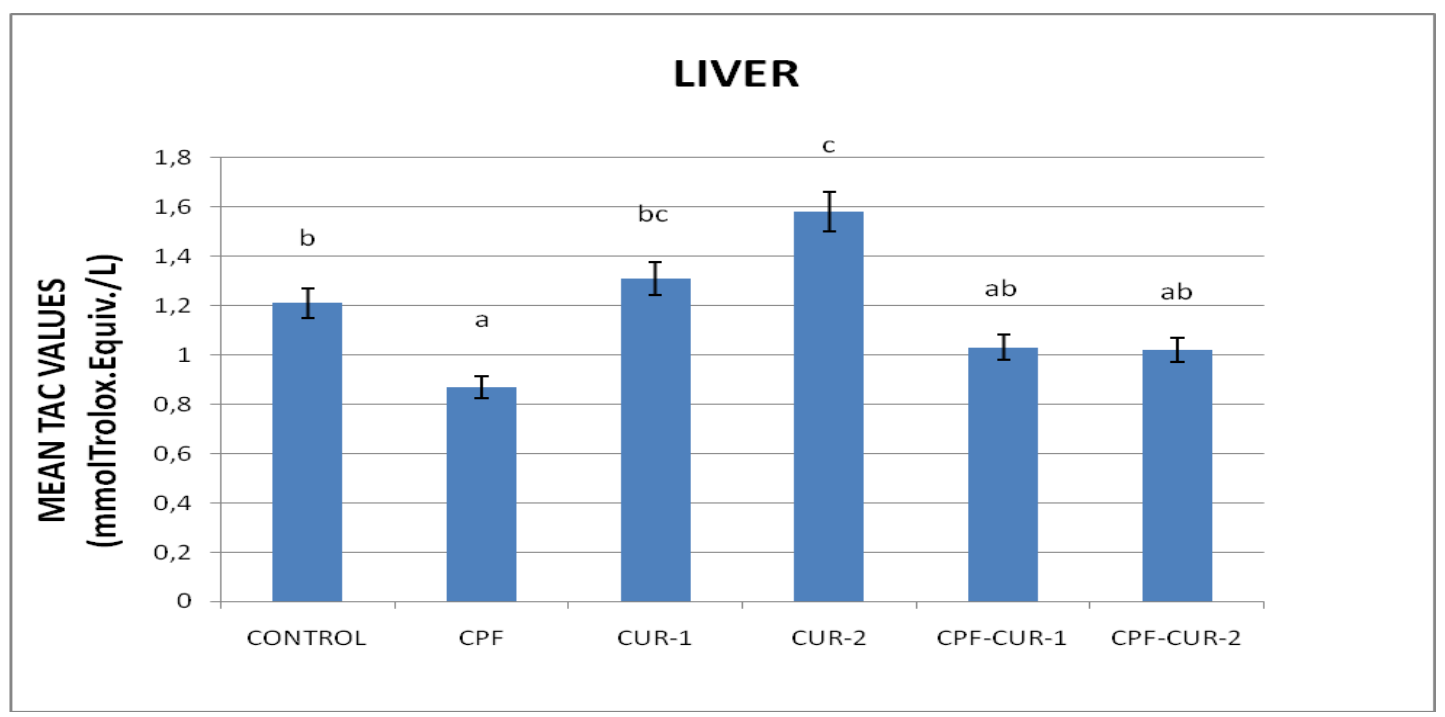

Figure 5. Effect of CPF and Curcumin on TAC values of liver tissue in O. mykiss $(n=10)$. Control: The fish was fed with pellet without additives. CFP (Chlorpyrifos): The group was exposed to water containing $0.040 \mathrm{mg} / \mathrm{l} \mathrm{CPF}$. CUR1: The group received only $0.5 \%$ Curcumin. CUR2: The group received only 1\% Curcumin. CPF + CUR1: The group was exposed to water containing $0.040 \mathrm{mg} / \mathrm{CPF}$, giving Curcumin at a rate of $0.5 \%$ of the total weight of the fish. $C P F+C U R 2:$ The group was exposed to water containing $0.040 \mathrm{mg} / \mathrm{CPF}$, giving Curcumin at $1.0 \%$ of the total weight of the fish. All data are presented in mean $\pm S E(n=20)$. abc: Bars bearing common letters are not statistically different $(p>0.05)$. There was a significant difference between the groups ( $p<0.001)$ 


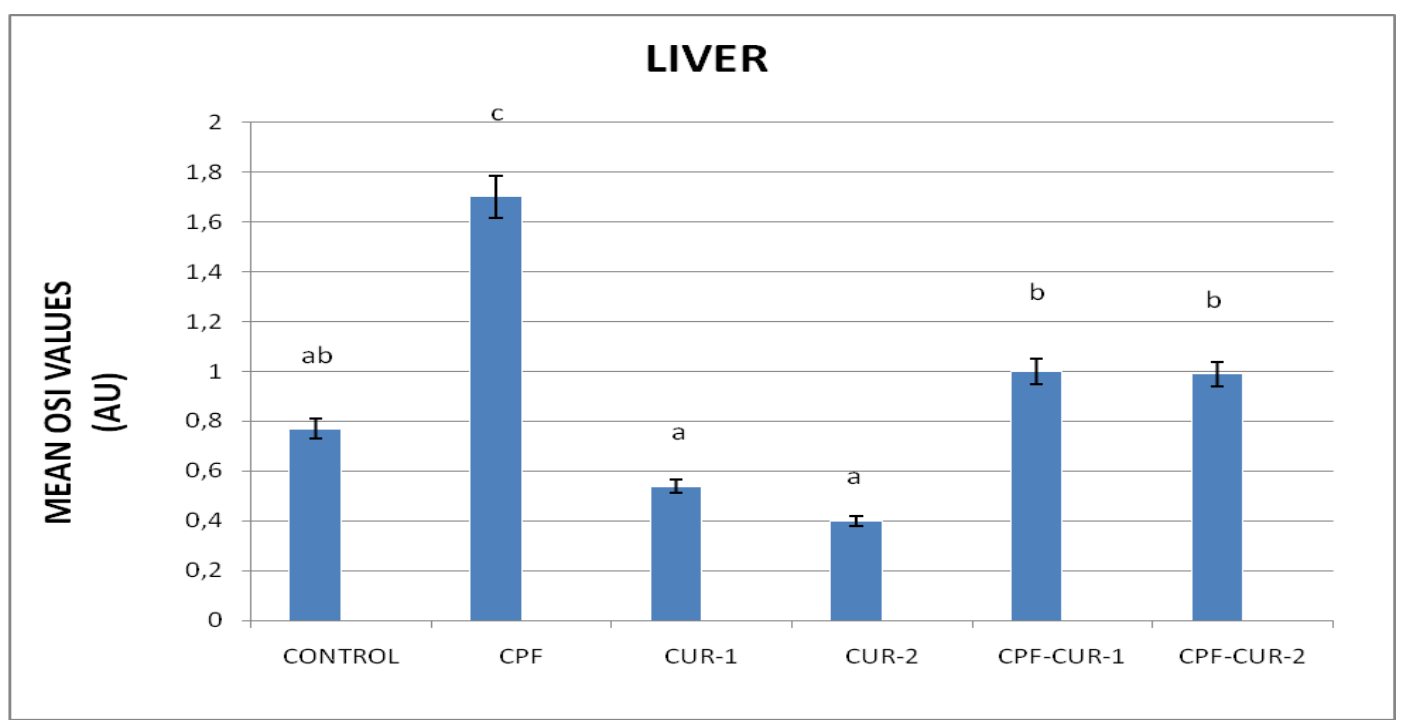

Figure 6. Effect of CPF and Curcumin on OSI values of liver tissue in O. mykiss $(n=10)$. Control: The fish was fed with pellet without additives. CFP (Chlorpyrifos): The group was exposed to water containing $0.040 \mathrm{mg} / \mathrm{CPF}$. CUR1: The group received only 0.5\% Curcumin. CUR2: The group received only $1 \%$ Curcumin. CPF + CUR1: The group was exposed to water containing $0.040 \mathrm{mg} / \mathrm{l} C P F$, giving Curcumin at a rate of $0.5 \%$ of the total weight of the fish. $C P F+C U R 2:$ The group was exposed to water containing $0.040 \mathrm{mg} / \mathrm{l} C P F$, giving Curcumin at $1.0 \%$ of the total weight of the fish. All data are presented in mean $\pm S E(n=20)$. abc: Bars bearing common letters are not statistically different $(p>0.05)$. There was a significant difference between the groups $(p<0.001)$

The results of the examined parameters of gill tissue are given in Figure 7, 8 and 9. In the gills, the TOS were significantly higher $(p<0.001)$ in the CPF and CPF + CUR-1 groups when compared to the control. The TOS in both CUR and CPF + CUR-2 groups were similar to those of the control group. The TAC in the all groups in the gill was not found to be significant when compared to control group. Only the gill TAC value of the fish given CUR at \% 1 was higher than the fish that received $0.5 \%$ CUR with CPF $(p<0.05)$.

The gill OSI values were significantly higher $(p<0.01)$ in the CPF + CUR-1 group when compared to the control. OSI values of fish fed both doses of CUR were significantly lower than that of fed the CPF + CUR-1 group $(p<0.05)$. The OSI in gill in fish fed at a dose of $0.5 \%$ of CUR were lower than the fed with CPF and CPF + CUR-1.

\section{Discussion}

$\mathrm{CPF}$ is one of the environmental toxicants, and hepatoxicity, genotoxicity, behavioral toxicity, neurotoxicity have been reported in fish (Deb and Das, 2013). Blood and liver is an important indicator for evaluating the physiological and pathological conditions in the organism when exposed to environmental pollution. Free radicals attack the membrane components of erythrocytes and cause a change in membrane structure and function (Prieto et al., 2006; Cunha-Oliveira et al., 2013; Mustafa, 2016). In order to test the oxidative stress in vivo, TOS, TAC and OSI were used in the blood serum, liver and gill tissues. 


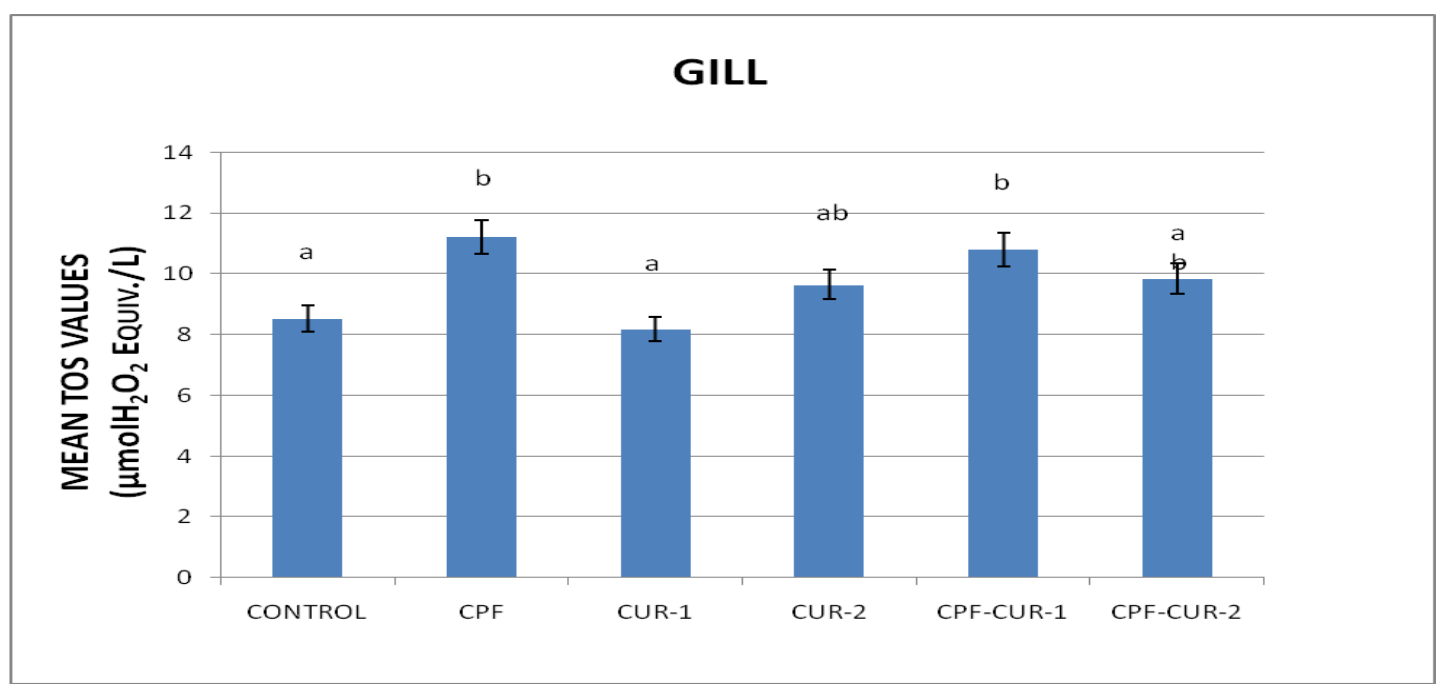

Figure 7. Effect of CPF and Curcumin on TOS values of gill tissue in O. mykiss $(n=10)$. Control: The fish was fed with pellet without additives. CFP (Chlorpyrifos): The group was exposed to water containing $0.040 \mathrm{mg} / \mathrm{CPF}$. CUR1: The group received only $0.5 \%$ Curcumin. CUR2: The group received only 1\% Curcumin. CPF + CUR1: The group was exposed to water containing $0.040 \mathrm{mg} / \mathrm{CPF}$, giving Curcumin at a rate of $0.5 \%$ of the total weight of the fish. $C P F+C U R 2:$ The group was exposed to water containing $0.040 \mathrm{mg} / \mathrm{l} C P F$, giving Curcumin at $1.0 \%$ of the total weight of the fish. All data are presented in mean $\pm S E(n=20)$. abc: Bars

bearing common letters are not statistically different $(p>0.05)$. There was a significant difference between the groups $(p<0.001)$

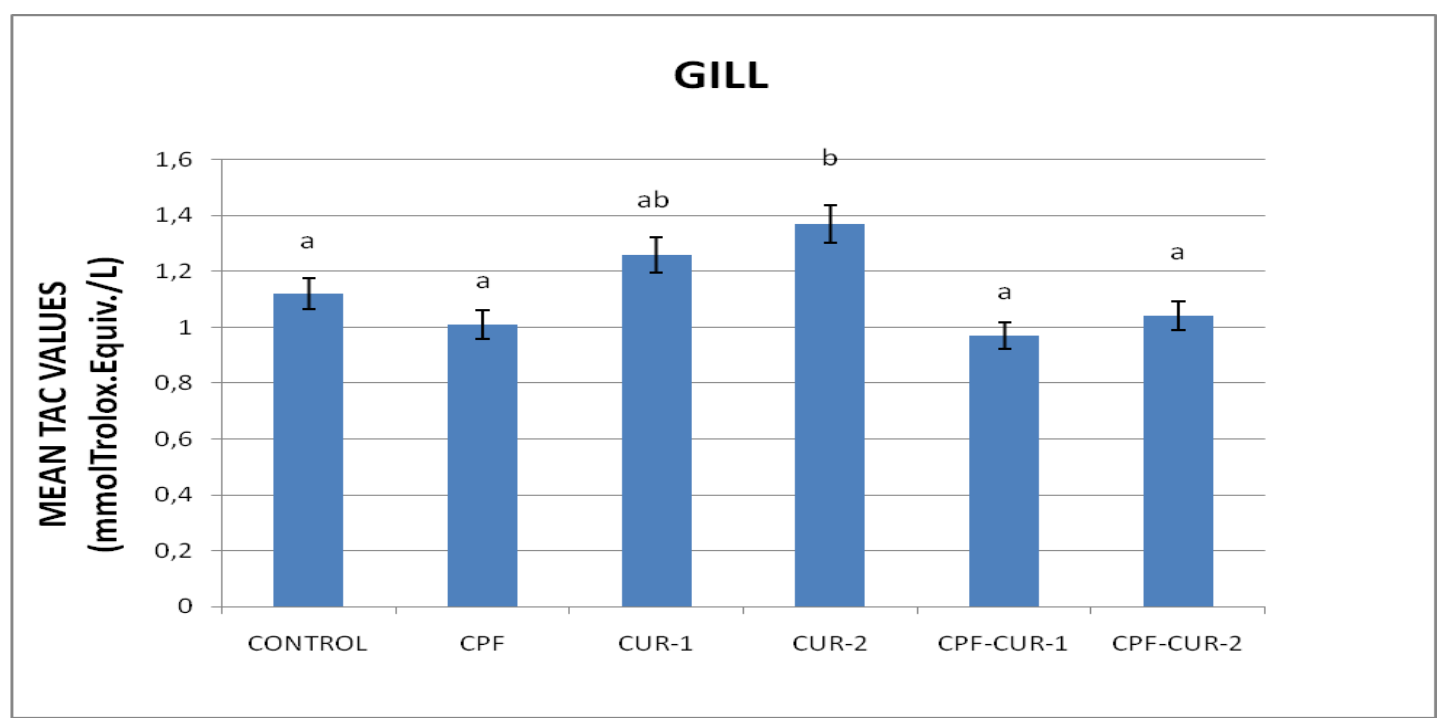

Figure 8. Effect of CPF and Curcumin on TAC values of gill tissue in O. mykiss $(n=10)$. Control: The fish was fed with pellet without additives. CFP (Chlorpyrifos): The group was exposed to water containing $0.040 \mathrm{mg} / \mathrm{CPF}$. CUR1: The group received only $0.5 \%$ Curcumin. CUR2: The group received only $1 \%$ Curcumin. CPF + CUR1: The group was exposed to water containing $0.040 \mathrm{mg} / \mathrm{l} C P F$, giving Curcumin at a rate of $0.5 \%$ of the total weight of the fish. $C P F+C U R 2:$ The group was exposed to water containing $0.040 \mathrm{mg} / \mathrm{l} C P F$, giving Curcumin at $1.0 \%$ of the total weight of the fish. All data are presented in mean $\pm S E(n=20)$. abc: Bars bearing common letters are not statistically different $(\mathrm{p}>0.05)$. There was a significant difference between the groups $(\mathrm{p}<0.001)$ 


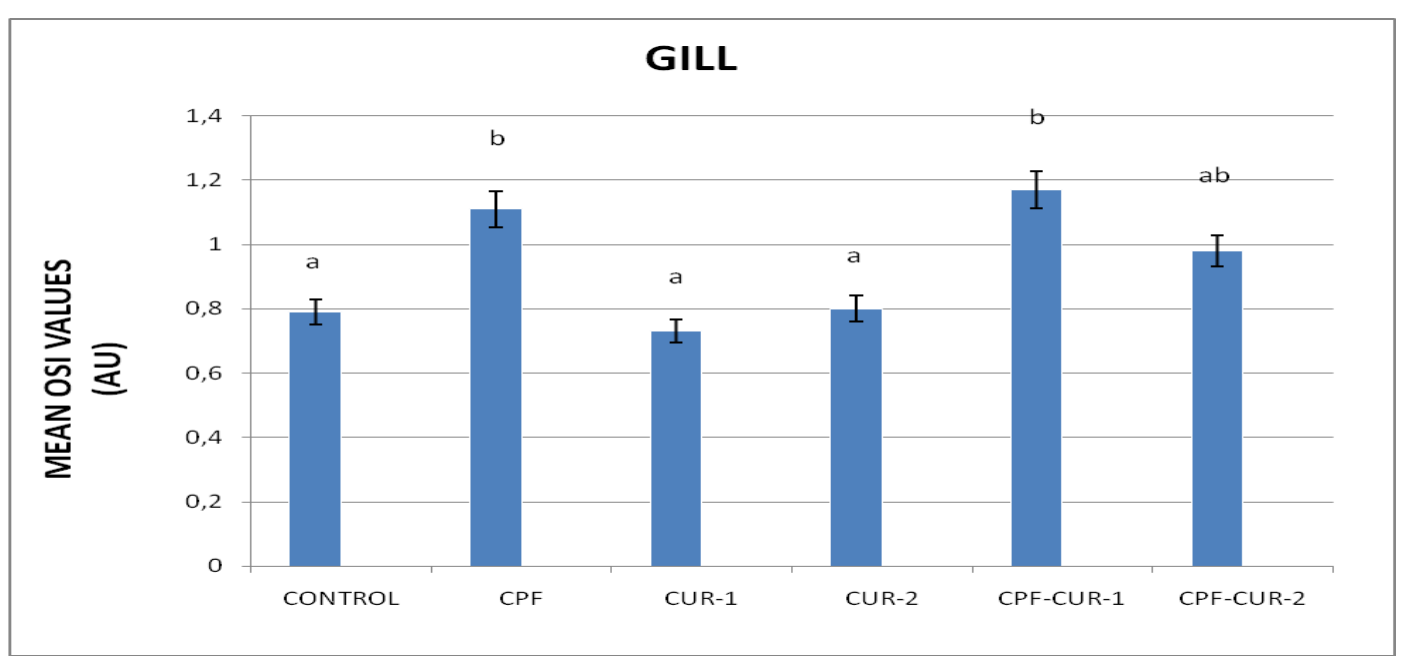

Figure 9. Effect of CPF and Curcumin on OSI values of gill tissue in O. mykiss $(n=10)$.

Control: The fish was fed with pellet without additives. CFP (Chlorpyrifos): The group was exposed to water containing $0.040 \mathrm{mg} / \mathrm{CPF}$. CUR1: The group received only $0.5 \%$ Curcumin. CUR2: The group received only 1\% Curcumin. CPF + CUR1: The group was exposed to water containing $0.040 \mathrm{mg} / \mathrm{CPF}$, giving Curcumin at a rate of $0.5 \%$ of the total weight of the fish. $C P F+C U R 2:$ The group was exposed to water containing $0.040 \mathrm{mg} / \mathrm{l} C P F$, giving Curcumin at $1.0 \%$ of the total weight of the fish. All data are presented in mean $\pm S E(n=20)$. abc: Bars bearing common letters are not statistically different $(p>0.05)$. There was a significant difference between the groups $(p<0.001)$

The results showed that CPF increased levels of TOS and OSI in blood serum. When CUR was given alone and in combination with CPF, TOS values were similar to the control group. These results showed that CPF alone increased oxidative stress and CUR reduced oxidative stress when the combination of CPF and CUR is given. CUR given alone did not have a significant effect on TOS and OSI levels. Therefore, CUR may be thought to have oxidative stress-reducing effect caused by CPF. Previous studies have similarly reported that the toxic effects of various toxicants such as metal, solvent and 6-OHDA are weakened by CUR (Yadav et al., 2010; Jaisin et al., 2011; Yang et al., 2014). The superiority of TAC test is to show the antioxidant capacity of all the antioxidants in the sample (Kusano and Ferrari, 2008; Hismiogullari et al., 2015). In the present study, $0.5 \%$ and 1.0 levels of CUR did not change the level of blood serum TAC according to the control group. TAC level in CPF and CPF + CUR-1 groups were similar to control group. TAC level in CPF + CUR-2 groups were lower that of the control. These results indicate that CUR does not have a significant effect on blood antioxidant levels in fish at these levels in feed. However, it has been reported that CUR has antiradical/antioxidant activity and potential cell regenerative properties (Mustafa, 2016; Karahan et al., 2016). In fact, the combined delivery of CPF and 1.0\% of CUR significantly reduced TAC levels compared to the control group. Thus, it can be said that when high levels of CUR combined with toxic substances reduces the level of antioxidants.

Oxidant and antioxidant levels in liver homogenates can be used as a marker of hepatocellular sensitivity. In the present study, liver TOS and OSI levels increased significantly while TAC levels decreased in CPF-treated fish compared to controls. Free 
radicals and ROS are key factors in cell damage. These factors have been shown to impair function and structural integrity in a few cells (Estebe et al., 2011; Karahan et al., 2016). Reactive oxygen species and lipid peroxidation lead to degradation in membranes and protein liver cells. Microcystin's (MCs) toxicity has been shown to increase lipid peroxidation as an indicator of oxidative damage in Brycon amazonicus liver homogenates (Martins et al., 2017). Furthermore, $0.5 \%$ and $1.0 \%$ levels of CUR reduce the TOS levels, while $1.0 \%$ level of CUR increased the TAC levels significantly. In addition, this is an indication of non-hepatotoxic potential of both doses of CUR. When both amounts of CUR (CPF + CUR-1 and CPF + CUR-2) were given in combination with $\mathrm{CPF}$, the TOS level significantly decreased compared to the CPF alone. This shows that antioxidants derived from CUR are used in the liver to reduce the effects of oxidation of the liver caused by CPF. Furthermore, it may be suggested that CUR has a hepatoprotective effect against toxic substances such as CPF. The CUR antioxidant activity is due to 2 phenolic $\mathrm{OH}$ groups (Prasad et al., 2014. These phytochemicals may have increased levels of cellular antioxidants and increased levels of antioxidants (Dinkova-Kostova et al., 2000). Intraperitoneal application of CUR and dexmedetomidine in rats has been shown to reduce ischemia-reperfusion injury and oxidative stress in the kidney (Karahan et al., 2016).

The TOS values in the gill homogenate were higher only in the CPF and CPF + CUR-1 groups than in the control group. CUR did not cause significant changes in TOS values in the gills, compared to control. Similarly, TAC levels of all groups were similar to control groups. CPF increased TOS levels by causing oxidative damage in the gills. CUR has not been able to reduce oxidative damage in the gills and has not been associated with antioxidant levels. These results suggest that antioxidant activity is limited in the gills. Similarly, the gill GPx activity of Brycon amazonicus (Martins et al., 2017) and O. niloticus (Prieto et al., 2006) exposed to microcystin toxicity has been altered but significantly increased in the liver. Martins et al. (2017) reported oxidative damage to Microcystin toxicity in the gills of Brycon amazonicus. CUR has been shown to inhibit and stimulate apoptotic signaling (Khar et al., 1995; Somasundaram et al., 2002). CUR may induce oxidative damage by caspase-3 activation. However, the mechanism of CUR that causes the induction of ROS formation is not fully understood (Hsuuw et al., 2005).

As you seen in the findings, the OSI can better point out the oxidative stress status. For this reason, TAS and TOS could be determined and then OSI values should be calculated. This could be more beneficial for estimation of comprehensive oxidative stress status (Wu et al., 2017). Intraperitoneal application of CUR and dexmedetomidine in rats has been shown to reduce ischemia-reperfusion injury and oxidative stress in the kidney.

\section{Conclusions}

The results of the research show that the level of antioxidants varies among tissues and is highest in the liver. It was observed that the dose of $0.040 \mathrm{mg} / \mathrm{l} \mathrm{CPF}$ at toxic level increased the oxidation level and lowered the antioxidant level of blood and liver in fish but not having any effect on the gill antioxidant level. CUR, given at a rate of $0.5 \%$ according to the live weight, increased the antioxidant level in the blood serum. In the presence of toxic substances such as CPF, CUR can also trigger oxidation in blood. The effect of CUR on tissues is not stable, but may increase the level of antioxidants or 
oxidants, depending on the presence of toxic substances such as CPF, tissue and the amount of toxic substances in feed. Also, our findings were showed that oxidative stress index could be often used as an indicator of oxidative stress in trout. Future studies should focus on molecular mechanism involved in protective effect of CUR on CPFinduced cell damage.

Acknowledgements. We would like to thank Harran University Scientific Research Coordination Unit [Project Number 16213] for supporting this research.

Ethics statement. All experiments were conducted according to the principles of the Ethics Committee for the Protection of Animals in Research of the Dollvet A.Ş. (Protocol No: 2014/61).

\section{REFERENCES}

[1] Akdemir, F., Orhan, C., Tuzcu, M., Sahin, N., Juturu, V., Sahin, K. (2016): The efficacy of dietary curcumin on growth performance, lipid peroxidation and hepatic transcription factors in rainbow trout Oncorhynchus mykiss (Walbaum) reared under different stocking densities. - Aquaculture Research 48: 4012-4021.

[2] Bala, K., Tripathy, B. C., Sharma, D. (2006): Neuroprotective and antiageing effects of curcumin in aged rat brain regions. - Biogerontology 7: 81-9.

[3] Burgeot, T., His, E., Galgani, F. (1995): The micronucleus assay in Crassostera gigas for the detection of seawater genotoxicity. - Mutation Research 342: 125-140.

[4] Cao, L., Ding, W., Du, J., Jia, R., Liu, Y., Zhao, C., Shen, Y., Yin, G. (2015): Effects of curcumin on antioxidative activities and cytokine production in Jian carp (Cyprinus carpio var. Jian) with CCl4-induced liver damage. - Fish \& Shellfish Immunology 43: 150-157.

[5] Cunha-Oliveira, T., Silva, L., Silva, A. M., Moreno, A. J., Oliveira, C. R., Santos, M. S. (2013): Acute effects of cocaine, morphine and their combination on bioenergetic function and susceptibility to oxidative stress of rat liver mitochondria. - Life Science 92: 24-26.

[6] Dağ, S., Aykaç, T., Gündüz, A., Kantarc1, M., Şişman, N. (2000): Turkey’s Agricultural Chemicals Industry and Its Future. V. Turkey Agricultural Engineering Technical Conference Proceedings, Volume 2. - TMMOB Chamber of Agricultural Engineers, Ankara 17-21: 933-958. (Türkiye' de Tarım İlaçları Endüstrisi ve Geleceği. V. Türkiye Ziraat Mühendisliği Teknik Kongresi Bildirileri 2. Cilt. - TMMOB Ziraat Mühendisleri Odas1).

[7] Deb, N., Das, S. (2013): Chlorpyrifos Toxicity in Fish. A Review. - Current World Environment 8(1): 77-84.

[8] Dinkova-Kostova, A. T., Holtzclaw, W. D., Cole, R. N., Itoh, K., Wakabayashi, N., Katoh, Y., Yamamoto, M., Talalay, P. (2000): Direct evidence that sulfhydryl groups of Keap1 are the sensors regulating induction of phase 2 enzymes that protect against carcinogens and oxidants. - Proceedings of the National Academy of Sciences 99: 1190811913.

[9] Doğu, Z., Şahinöz, E., Aral, F., Çelik, H., Koyuncu, İ., Taşkın, A., Aksoy, N. (2015): Pesticide-contaminated feeds in rainbow trout (Onchorhyncus mykiss W. 1792) aquaculture: Oxidative stress and DNA damage. - Pakistan Journal of Zoology 47(3): 815-821.

[10] Duan, W., Yang, Y., Yan, J., Yu, S., Liu, J., Zhou, J. (2012): The effects of curcumin post-treatment against myocardial ischemia and reperfusion by activation of the JAK2/STAT3 signaling pathway. - Basic Research in Cardiology 107: 263. 
[11] Elazığ Provincial Directorate of Agriculture (2004): Managed Farmer Pesticide Challenge Need List According to 2004 Program. (Elazığ Tarım İl Müdürlüğü. (2004): 2004 Y1l1 Programına Göre Yönetimli Çiftçi Pestisit Mücadele İhtiyaç Listesi). - Provincial Directorate of Agriculture, Elazı $\breve{g}$.

[12] Erel, O. (2005): A new automated colorimetric method for measuring total oxidant status. - Clinical Biochemistry 38: 1103-1111.

[13] Estebe, J. P., Davies, J. M., Richebe, P. (2011): The pneumatic tourniquet: Mechanical, ischaemia-reperfusion and systemic effects. - European Journal of Anaesthesiology 28: 404-411.

[14] Fuhrer, E., Rudolph, A., Espinoza, C., Diaz, R., Gajardo, M., Camano, N. (2012): Integrated use of biomarkers (O: $\mathrm{N}$ ratio and acetylcholinesterase inhibition) on Aulacomya ater (Molina, 1782) (Bivalvia: Mytilidae) as a criteria for effects of organophosphate pesticide exposition. - Journal of Toxicology. http://dx.doi.org/10.1155/2012/951568.

[15] Girón-Pérez, M. I., Barcelós-García, R., Vidal-Chavez, Z. G., Romero-Bañuelos, C. A., Robledo-Marenco, M. L. 2006: Effect of chlorpyrifos on the hematology and phagocytic activity of Nile tilapia cells (Oreochromis niloticus). - Toxicology Mechanisms and Methods 16(9): 495-499.

[16] Goel, A., Danni, V., Dhawan, D. K. (2005): Protective effects of zinc on lipid peroxidation Antioxidant enzymes and hepatic histoarchitecture in chlorpyrifos-induced toxicity. - Chemico-Biological Interactions 156: 131-140.

[17] Hismiogullari, A. A., Hismiogullari, S. E., Karaca, O., Sunay, F. B., Paksoy, S., Can, M., Kus, I., Seyrek, K., Yavuz, Ö. (2015): The protective effect of curcumin administration on carbon tetrachloride (CCl4)-induced nephrotoxicity in rats. - Pharmacological Reports 67(3): 410-416.

[18] Hsuuw, Y. D., Chang, C. K., Chan, W. H., Yu, J. S. (2005): Curcumin prevents methylglyoxal-induced oxidative stress and apoptosis in mouse embryonic stem cells and blastocysts. - Journal of Cellular Physiology 205: 379-386.

[19] Jaisin, Y., Thampithak, A., Meesarapee, B., Ratanachamnong, P., Suksamrarn, A., Phivthong-Ngam, L., Phumala-Morales, N., Chongthammakun, S. (2011): Curcumin I protects the dopaminergic cell line SH-SY5Y from 6-hydroxydopamine-induced neurotoxicity through at tenuation of p53-mediated apoptosis. - Neuroscience Letters 489: 192-196.

[20] Kammerbauer, J., Moncada, J. (1998): Pesticide residue assessment in three selected agricultural production systems in the Choluteca River Basin of Honduras. Environmental Pollution 103: 171-181.

[21] Karacan, A. R. (2007): Çevre Ekonomisi ve Politikası. - Ege Üni. Yayınları. No. 6, İzmir.

[22] Karahan, M. A., Yalcin, S., Aydogan, H., Büyükfirat, E., Kücük, A., Kocarslan, S., Yüce, H. H., Taskın, A., Aksoy, N. (2016): Curcumin and dexmedetomidine prevents oxidative stress and renal injury in hind limb ischemia/reperfusion injury in a rat model. - Renal Failure 38(5): 693-698.

[23] Khar, A., Ali, M., Pardhasaradhi, B. V. V., Begum, Z., Anjum, R. (1999): Antitumor activity of curcumin is mediated through the induction of apoptosis in AK-5 tumor cells. - FEBS Letters 445(1): 165-168.

[24] Kusano, C., Ferrari, B. (2008): Total antioxidant capacity: a biomarker in biomedical and nutritional studies. - J Cell Mol Biol. 7: 1-15.

[25] Malkovics, B. (1995): Effect of organophosphates on the antioxidant systems of fish tissue. - Acta Biologica Hungarica 9: 11.

[26] Manju, M., Akbarsha, M. A., Oommen, O. V. (2012): In vivo protective effect of dietary curcumin in fish Anabas testudineus (Bloch). - Fish Physiology and Biochemistry 38: 309-318. 
[27] Martins, N. D., Yunes, J. S., Monteiro, D. A., Rantin, F. T., Kalinin, A. L. (2017): Microcystin-LR leads to oxidative damage and alterations in antioxidant defense system in liver and gills of Brycon amazonicus. - Toxicon 139: 109-116.

[28] Morimoto, T., Sunagawa, Y., Kawamura, T., Takaya, T., Wada, H., Nagasawa, A. (2008): The dietary compound curcumin inhibits p300 histone acetyltransferase activity and prevents heart failure in rats. - Journal of Clinical Investigation 118: 868-878.

[29] Mustafa, H. N. (2016): The role of curcumin in streptozotocin-induced hepatic damage and the trans-differentiation of hepatic stellate cells. - Tissue and Cell 48(2): 81-88.

[30] Naik, S. R., Thakare, V. N., Patil, S. R. (2011): Protective effect of curcumin on experimentally induced inflammation, hepatotoxicity and cardiotoxicity in rats: evidence of its antioxidant property. - Experimental and Toxicological Pathology 63: 419-31.

[31] Nirmala, C., Anand, S., Puvanakrishnan, R. (1999): Curcumin treatment modulates collagen metabolism in isoproterenol induced myocardial necrosis in rats. - Molecular Cellular Biochemistry 197: 31- 37.

[32] Prasad, S., Tyagi, A. K., Aggarwal, B. B. (2014): Recent developments in delivery, bioavailability, absorption and metabolism of curcumin: the golden pigment from golden spice. - Cancer Research and Treatment 46: 2-18.

[33] Prieto, A. I., Jos, A., Pichardo, S., Moreno, I. M., Camean, A. M. (2006): Differential oxidative stress responses to microcystins LR and RR in intraperitoneally exposed tilapia fish (Oreochromis sp.). - Aquatic Toxicolology 77: 314-321.

[34] Sanchez-Galan, S., Linde, A. R., Izquierdo, J. I., García-Vázquez, E. (1998): Micronuclei and flactuating assymetry in brown trout (Salmo trutta): complementary methods to biomonitor freshwater ecosystems. - Mutation Research 412: 219-225.

[35] Sharma, Y., Bashir, S., Irshad, M., Datta Gupta, S., Dogra, T. D. (2005): Effect of acute dimethoate administration on antioxidant status of liver and brain of experimental rats. Toxicology 206: 49-57.

[36] Somasundaram, S., Edmund, N. A., Moore, D. T., Small, G. W., Shi, Y. Y., Orlowski, R. Z. (2002): Dietary curcumin inhibits chemotherapy-induced apoptosis in models of human breast cancer. - Cancer Research 62(13): 3868-3875.

[37] Sreejayan, Rao, M. N. (1997): Nitric oxide scavenging by curcuminoids. - Journal of Pharmacy and Pharmacology 49: 105-107.

[38] Srivastava, G., Mehta, J. L. (2009): Currying the heart: curcumin and cardioprotection. Journal of Cardiovascular Pharmacology and Therapeutics 14: 22-27.

[39] Wu, R., Jiafu, F., Yuwei, Y., Chunmei, D., Anyang, L., Jie, L., Yao, L., Miao, X., Qingmei, H., Dong, W., Xiao-Bo, D. (2017): Significance of serum total oxidant/antioxidant status in patients with colorectal cancer - PLoS One 12(1): e0170003. (1): 1-13.

[40] Yadav, R. S., Shukla, R. K., Sankhwar, M. L., Patel, D. K., Ansari, R. W., Pant, A. B., Islam, F., Khanna, V. K. (2010): Neuroprotective effect of curcumin in arsenic-induced neurotoxicity in rats. - Neurotoxicology 31: 533-539.

[41] Yang, J., Song, S., Li, J., Liang, T. (2014): Neuroprotective effect of curcumin on hippocampalinjury in 6-OHDA-induced Parkinson's disease rat. - Pathology - Research and Practice 210: 357-362.

[42] Zámocký, M., Koller, F. (1999): Understanding the structure and function of catalases: clues from molecular evolution and in vitro mutagenesis. - Progress in Biophysics and Molecular Biology 72(1): 19-66. 